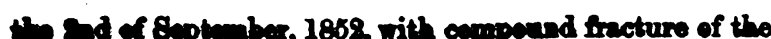
as frontis, cansed by a blor from a readte of a winch in inlent motion on board of a vereel in cee of the docks. The coternal wound was about two inches in length over the ingt eje-brow. The bone was fractured across; the upper portion was depressed, and the lower, as it were, lapping over it. When the man came in he was perfectly sensible, and there were no symptoms of compression. It was considered, under thee circumstances, that the best plan would be not to interfere by an operation, but to leave the case alone, and only to treat symptoms as they occurred. He went on to all appearances favourably for four weeks, when he became Jow and dejected; previously he had felt cold, and had a rigor.

It was supposed at the time that he had got low spirited in consequence of his friends, who were in the habit of coming to the hospital to see him, being obliged to leave with the vessel. On the 2nd of October, he was dejected and would hardly speak; but on the following morning he became insensible, and was labouring under symptoms of compression. A consultation was called, and it was agreed that the depressed portion of bone should be elevated. Her's san was used; and the other part was elevated, still after this there was no evident good result; but on feeling the dura mater, fluctuation was felt under the finger; an opening was made into it, when a quantity of pus came out. The breathing became somewhat better, and the pulse quicker, but no sign of returning consciousness appeared. The patient died that night.

On examination of the body, on October 5th, an abscess of about the size of a pigeon's egg was found in the anterior lobe of the cerebrum, exactly under the seat of the fracture, containing a quantity of pus.

REMARK8. In all the foregoing cases of compound fracture of the skull with depression, a portion of bone was wedged firmly under another portion, and driven in the depth of the elerated part of the fracture; and all of them were accompanied with laceration of the integuments over the seat of the injury. In none of the cases were there complete symptoms of compression; still it was deemed advisable to perform the operation of trephining, and that with the most happy result. It has been recommended for many years past, by authors of considerable eminence, never to interfere by an operation when the depression of bone is unaccompanied with symptoms of compression. Howerer, I have seen this plan adopted on several previous occasions with very unfavourable results, when to all appearance, for three weeks or a month, the cases were progressing satisfactorily; symptoms of compression would then manifest themselves, and perhaps at this time the trephine would most likely be applied; in my opinion, at too late a period to be attended with any advantage, the long continued pressure causing irritation and slow inflammation of the parts underneath, terminating in suppuration and death. Mr. Pott gives the reasons why, in his opinion, the practice of trepanning should be adopted in fractures of the skull. He says: "It is true, in many cases, that fractures of the skull are not attended with any symptoms that actually require this operation at the moment; but, although there may be no symptoms denoting affection of the membranes or of the brain, that inflammation of those parts will come on at a more or less remote period of time, and therefore the operation should be had recourse to, in order to prevent the occurrence of such inflammation."

An eminent living surgeon, in one of his lectures on fractures of the skull, speaks in the following manner as to the line of practice to be pursued in such cases, and which has been generally practised for the last thirty years:-

"In the present day, we have entirely discarded the doctrine of employing the trephine, or instruments of any sort, in all kinds of fractures of the skull, and consider it as a meacure that we are not to have recourse to, except where there is depression of the bone, and that depression of the bone sccompanied with symptoms of preasure of the brain."

In freture of the okull without depreacion of the bone, so wont think of epplying the trephine; but when there is the depreacion weh as that I have attempted to dosaribe, although there may not be any symptoms of campreseion, in my opinion it is the safeet practice to elevate the depreased portion of bone as carly as possible after the accident, and eepecinlly if the fracture is exposed. If it be allowed to remain, it is only a source of irritation in a great many instances, producing inflammation of the dure matar and the brain, ending in suppuration; and if the trephine is applied at this period, it is seldom attended with succem. This is the result of $\mathrm{my}$ experience in cases of this doseription.

Liverpool, February 4, 1854.

\section{THE CONDITION OF THE RESPIRATION IN DISEASE.}

By SAMUEL WILKS, M.D.Lond., Physician to the Surrey Dispensary.

HAVING for many years been in the habit of noting the number of respirations in cases of disease, $I$ intend, in the present communication, to show the marked increase it undergoes in all febrile affections-a fact not mentioned in many treatises among the category of symptoms which accompany these conditions. I was first led particularly to mark the state of breathing upon reading, in Carpenter's Physiology, that sometimes in typhus the number of respirations is depressed from the influence of the morbid poison on the nervous system. Feeling that all my observations had never led me to such a conclusion, I carefully took notes of a large number of cases of fever, and found that my former experience was invariably verified.

It requires a little consideration to see clearly on what the number of respirations, either in health or disease, depends. The amount of the respiratory process might, I think, be correctly stated to be dependent upon the amount of blood to be aerated, or, in more precise terms, the degree of the respiratory process would be a measure of the amount of effete matter in the blood, or that part of it which is brought to the lungs. The impurity of the blood, and consequent increased work of the lungs, would depend upon many causes, the wear and tear of the body, various morbid conditions, the derangement of other organs, etc. The only means for measuring accurately the amount of work done, would be by the spirometer, which should calculate the quantity of carbonic acid and vapour given off by the lungs. I am not aware that of late any very lengthened or systematic observations have been made on this subject, and those formerly published by various experimenters were scanty, and to some extent contradictory ; but that the function of respiration varies in different diseases, there cannot be a doubt. From all analogy, from the condition of other organs in disease, as the kidney and urine in febrile affections, it is just to suppose that the excrementitious matter in the blood is at one time more in quantity than at another, and consequently the lungs would have to take their part in an increased effort to remove it. One measure of the amount of aeration done by the lungs is the number of the respirations. For example: if a man breathing a certain number in a minute walks quickly, or exerts himself, and the number is increased, it is fair to suppose that during such time the whole respiratory process has been exalted; and this has been found by actual experiment to be true. The number of respirations, however, in itself is by no means a measure of the amount of the respiratory process. In children and infants, the number is much greater than in adults: also in the same person, from some accidental cause, the number may be augmented, when it is not probable that the funetion is increased. A pleurodynia, a pain in the abdomen or elsewhere, that is excited by a full inspiration, necessitates a shorter one; and, as a consequence, a larger number is required to make up the deficiency. Thus, two short inspirations may be oquivalent to one deep one. In nervous hysterieal women, we aften 800 the whole cheat not fully 
cipandod, and quiol hom inopintiong, intarupted with ithing, are required to malte up the doficienes. Again, too, if the luns iteolf is impaired, 80 that only a part onn wort, 2 in phthisis, or from the pressure of a plouritic efinion, an increased number of repirations is requisite. It is fer that a certain amount of aeration is required; and if the inspirations be small, they must be increased in number to make up the quantity. Thus, a phthisical patient may be breathing at a rate twice that which is natural, and yet be quite unsware of the circumstance. If an impediment occur to the passage of air into the lungs, then, besides a quickened, there is a difficult respiration. In diseases of the bronchial tubes, the dyspnces and shortness of breath are most marked, and the non-2eration of the blood is shown by the lividity of the skin and venous congestion of all parts. When the lungs are congested from heart disease, a difficulty arises in the same way. The besoin de respirer seems to depend upon the presence of renous blood in the lungs, which, while there, is ever seeking for air to purify it, in order to allow it to pass onward. In short breath, when no difficulty is experienced by the patient, and no lividity of the skin, we may suppose that the increased number of respirations makes up for the small individual ones. Whether the blood is sufficiently aerated, may be determined sometimes by another means, founded upon the well known experiments of Bernard upon the consumption of the hepatic sugar in the lungs. For example, a girl, eleven years of age, was the subject of plouro-pneumonia of one lung, which rendered for a time that organ altogether useless. The breathing was at the rate of 50-60 a minute, yet even this did not satisfy the wants of the system with a supply of sufficient air. For two weeks, while the respiration was 80 affected, the urine contained a very notable quantity of sugar, and which only disappeared upon the subsidence of the pulmonary affection.

$A$ diminished respiration is, as far as I know, always dopendent upon a cause in the nerrous system; and this, if not sufficient for the wants of the blood, produces a congestion in the lungs. Irately, there have been two cases under the care of Dr. Barlow, in Guy's Hospital, of disease at the base of the brain, which implicated the pneumogastric nerves. In one, the respirations became more and more difficult; and a copious bronchial secretion was poured forth, just as in Dr. Reid's experiments of the division of the nerve; and in the other case, a slow consolidation occurred from inflammation. The slow respiration produced by poisoning by opium is soon followed by a congestion of the lungs.

Apart, however, from all such causes as are above named, and many others which influence the breathing, an increased number of respirations must in many cases be taken as a proof of an increased function. When the lungs are healthy, and there is no impediment to a full inspiration, I take it that an increased number is significant of an increased action in those organs. Now, if the besoin de respirer is dependent upon the amount of blood to be aerated, or effete matter to be removed, an increase of morbid or excrementitious matter in the blood must necessitate a greater number of inspirations. This I suppose to be the case in fever, where, with healthy lungs, a more rapid breathing always oxists. In fact, in all febrile diseases, an increased number of respirations constantly prevails, and which I take as ovidence of an increased respiratory function. By any one who has not examined the subject, it might be thought that this was merely owing to the general excitement of the system, and was a part of the more rapid circulation. This, however, is not the case; for, admitting that the actions of the lungs and heart do, to a certain extent, influence each other, as is seen after violent exertion where each may be doubled, yet, as regards the number of each, in many diseases they are quite independent. One stroke of the heart throws out as much blood, whether that blood be comparatively pure, or loaded with effete material. In the latter case, however, more serntion and reapirntory corts would be required thin in the former. The action of the heart and lunge, then, depanding mainly upon diffor-

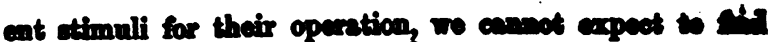
anj cometant rolution botween them.

The constent inerease in number of the repinaters cet, in all febrile diecese, I am surprised has not beon move dir tinctly stated by authors. In forer, it is the most censtant symptom, excepting al ways the nerrous depsecion, which is the only invariable phenomenon of this discace. I have before me a great many cases of ferer, with a dait report, among other conditions, of the pulse and the rospiration; and the latter shows very often much more marked change than the former. In an adult, the ratio of the respirations to the pulse is as 1 to $5 \frac{1}{2}$ or 6 , i. e, malring the pulse about 70, and the repirations 12-14 per minute; while in children, it is as 1 to 3 t or 4 ; and in young infants, as 1 to $2 \mathrm{t}$. In most cases of ferer (excluding of course those with pulmonic complication), the pulse being about 100 , the respiration is 25 or 30 per minute, being much higher ratio than in health; the proportion, in fact, is doubled, being as much as 1 to 3 . During the course of the fever, the respiration remains high, while the pulse may be natural, or below the standard; so that, in fact, no proportion can be obtained between them. A woman, aged 30 , with typhus fever, a mulberry rash, and no chest ar abdominal complication, had a pulse 116, while the respiration was 36 in the minute. The pulse soon became 100 , and the respiration 32 . The pulse sank next day to 90 , and afterwards still lower, until it reached 52; while the respiration had only reached 26 . The skin was still hot and dry. The pulse sank still lower, to 42 , while the respiration was 22. The respiration is there seen to be as much above the standard of health, as the pulse below it. Perspiration broke out, and the patient convalesced, when the pulse got up, and the respiration went down, until each had reached its natural standard. Such a case is an example of the rule in fever-the independent course of the heart and the lungs in reference to their own peculiax duties. A man now under notice, with typhus, had his pulse 132, and respiration 36. As he is improving, his pulse has fallen to 72 , while his respiration is still 24 ; the proportion between them being as 3 to 1 . When fever patients get very low, their breathing is often more rapid than this; but then other operating causes come in to produce the result, as the congested state of the lungs. In such a case, where at first the pulse was 104, and the respiration 26 , the patient sank down, until the respiration became 38 ; but, at the same time, the pulse receded to 96. During the recovery, a rapid diminution of the numbers of respiration took place, and reached 14, when the pulse had only got to 64 , and the patient convalescent. A man, with fever and great cerebral oppression, had his pulse for many days 44, while his respiration was 24. A woman with ferer had a pulse 64 , and respiration 32, or the former double the latter. As she progressed, the pulse remained the same for a fortnight, while the respiration gradually came down to the normal standard.

In other febrile diseases, I have found the result to be just the same, viz. that the numbers of respirations have always remained high, and out of all natural proportion to the pulse, while the ferer lasts. In the exanthemsta, as scarlatina, the result is the same as in common fever. As the skin and the lungs have to a certain extent a supplementary action, as regards the evolution of humidity, and even the aeration of the blood, I was anxious to find if the respiration was still high, when the skin was moist; and I found it to be as before stated, if febrile symptoms existed. In rheumatism, invariably, as in fever, the respirations are increased in number, and this altogether independent of the heart's action. The effect of lemon-juice in lowering the pulse is well known, and exemplified in two of the following cases. The following are the first six in my notebook of acute rheumatism:-In the first case, the pulve was 96, and the respiration 36. In the next, the pulse was 100 , and the respiration 30 . In'the next, the pulse was 88 , and respiration 28 . In the fourth cave, where was come cough and an old cardinc bruit, the pulse was 139, and the reopiration 40 . In the noxt tro, lomon-juies wes 
: no cheat symptoms, and profuse perspirations. In th former case, the pulce 130 110, and the respiration 40. On the following day, the pulse was 100, and the respiration 32. In three dajs, the pulse had fallen to 76, while the respiration was still 32. During convalescence, the pulse remained steady, while the respiration gradually subsided to 17. In the last case, where lemon-juice was given, the pulse was at first 120 , and the respiration 36 . The pulse in three days lowered to 70 , while the respiration had only reached 32. After three days more, the pulse was still 70, while the respiration had got down to 24 . The pulse was thus seen rapidly to fall under the use of a drug which influenced the heart, while the respiration took its own course slowly to descend.

I have mentioned sufficient cases to draw more particular attention to the fact, that the respiratory act is exalted in febrile disease, and in proportion to the fever, and is not dependent upon, or proportional to, the action of the heart. $\Delta_{8}$ I before said, I do not allude to those cases where any pneumonia, pleuritis, or bronchitis exists, or even that hypostatic congestion in fover, which approaches so nearly to inflammation. In all such inflammatory affections of the chest, the rapid increase of the respiration is well marked; and draws attention to the condition of the lungs, and is a sign, indeed, not to be overlooked, particularly in the course of chronic disease, and where the patient is not likely to make any complaint. The state of breathing, however, to which I have particularly drawn attention, is not so rapid that the medical attendant observes it at all, -it is only by watching the morements of the chest that ho becomes aware of their increased frequency.

I will just mention one or two other cases of disease to shew the independent action of the heart and lungs, the nervous influence conveyed to one being different from that conveyed to the other, and the two little affecting each other. During the last year, I have constantly seen a man the subject of some obscure cerebral affection, and who occasionally has fits of an epileptiform kind. His pulse is never more than 32, (and the heart's action corresponding); on one occasion it was 26 , but the number of his respirations is normal. A young man died of disease of the brain, and his pulse was sometimes as low as 56, though on excitement, it soon rose to 80 , and yet his respiration during this time was 28-30. A young child I lately saw with hydrocephalic disease, had its respiration never more than 20 , while the pulse was 120 .

The condition of the heart and lungs must then in disease be considered to a great extent separately; for although the two organs are intimately connected, each has its own independent function and action. In a case of extreme bronchitis, with great pulmonary congestion, and a general venous stagnation, the state of the radial artery is taken as a test of the condition of the circulatory system and of the powers of the patient. Although the veins may be full to bursting, bloodletting is not considered, because the arterial system denotes emptiness and weakness, and the heart feebleness. A stimulant is often given in such cases when the pulse is small, but which only increases the evil. I believe, in such cases, a small bloodletting would often be useful in relieving the circulation, merely by its mechanical effects, and which, I apprehend, to be the principal use of this remedy. The following is a good example of this treatment:-A stout boy, seven years old, who had a chronic cough after pertussis, and who was in a condition commonly called asthmatic, was one winter's day seized with increased difficulty of breathing. The symptoms rapidly became 30 severe that death was expected. The head was thrown back, the face and body were blue, the eyes protruding, the dyspncea excessive, the pulse quick and hardly to be felt, and a fatal issue evidently near at hand. The prominent jugular vein stood out temptingly. It was opened, some fer ounces of dark blood escaped, the congestion was very soon relieved, the breathing became tranquillized, the boy lay back and was soon in a sound sleep, and the next day was comparatively well. I mention this as an instance eremplifying how useful and often neces- ary it is to regard the pulmonic circulation more distinctly, and more spart from that of the general cireulation.

A very rapid respiration is generally indicative of an inflammatory affection of the lungs, unless it arise from a nervous cause, which is usually evident; and a difficult respiration accompanies affections of the air passages, and all causes which hinder a free ingress of air to the lungs. The purport of the present paper is to shew more distinctly the increased rapidity of respiration in all febrile disease, and which I take as an evidence of a temporarily increased function. Without, however, laying too much stress upon any of the theoretical statements I may have mentioned, I would at present only draw more particular attention to the fact, that in all febrile diseases, the number of respirations is much increased, and has a certain relation to the ferer, and that this symptom is as constant as any alteration in the character of the pulse, skin, urine, etc. A more detailed account of the state of respiration in disease, I shall reserve. for another communication.

St. Thomas Street, Southwark, Jan. 30th, 1853.

\section{PASSAGE OF NINETY-ONE GALL-STONES. THROUGH A SUPPOSED ULCERATED OPENING OF THE GALL-BLADDER INTO THE INTESTINE.}

\author{
By F. W. P. JAGO, M.B.Lond.
}

Dr. W., of Plymouth, was taken ill on the 28th Nov. 1853. $\mathrm{He}$ is about 37 years old, of a spare habit, and marked bilious temperament. He was formerly in large practice in Leicestershire; but, in consequence of ill-health, was about three years ago obliged to give it up. At the age of sirteen, he suffered a severe and protracted attack of jaundice, attended with considerable enlargement of the liver. At the age of twenty, while a student, he had an attack of "spasms", with jaundice, acute pain over the gall-bladder, incessant romiting, and obstruction of the bowels; so that his life was in great danger. These symptoms ceased on the passage of a gall-stone, of about the size of a filbert. The treatment consisted of repeated bleeding, the application of thirty leeches over the right hypochondriac region,. saline aperients, calomel, colocynth, and opiate injections. Restoration to health was protracted.

Since then, he has had an attack every other year, generally about the latter end of autumn or of spring, each illness lasting from seven to ten days; but no gall-stones had been passed or found. The treatment had been just as in the former case. In the intervals, Dr. W. had suffered much from indigestion, irritable bowels, and bilious diarrhoce, especially during the winter.

On the 28th of Norember last, he was seized with pain in the region of the gall-bladder, distension of the stomach, and total loss of appetite. On the 30th, there were severe spasms and much vomiting, with an increase of pain.

Dr. H. and myself attended at Dr. W.'s request. We found him labouring under the abore symptoms. The left lobe of the liver was apparently enlarged, with great tenderness in the epigastrium. After sleeplessness for fortyeight hours, a gall-stone of the size of a pea passed, followed by evident relief. The remedies were saline aporients, occasional doses of blue pill, hyoscyamus, hydrocyanic acid, and morphia suppositories.

The jaundice and enlargement in the region of the gallbladder continued to lessen for two or three days, and recovery appeared to go on favourably; but, on the 9 th of December, all the old symptoms returned with intense violence, and continued without intermission for several days. The spasms were insupportable; and the vomiting was incessant, with discharge of mucous and gaseous matter. Salines only could be retained for a minute or trro. On December 12th, there was a severe rigor, the tenderness and tumour over the gall-bladder being very great. These 